\title{
ON THE PREDICTION OF THE THERMAL CONDUCTIVITY OF SATURATED CLAYEY SOILS: EFFECT OF THE SPECIFIC SURFACE AREA
}

\author{
Adrian RÓŻAŃSKI *and Damian STEFANIUK \\ Wroclaw University of Science and Technology, Faculty of Civil Engineering \\ ul. Wybrzeże Wyspiańskiego 27, 50-370 Wroctaw, Poland
}

*Corresponding author's e-mail: adrian.rozanski@pwr.edu.pl

\begin{tabular}{l} 
ARTICLE INFO \\
\hline Article history: \\
Received 30 October 2015 \\
Accepted 4 May 2016 \\
Available online 6 June 2016 \\
\hline
\end{tabular}

\section{Keywords:}

Soil

Clay

Thermal conductivity

Specific surface area

Modelling

\begin{abstract}
The models for predicting thermal conductivity of soils are usually sensitive to the chosen value of the soil solid conductivity $\lambda_{s}$. Existing approaches of estimating $\lambda_{s}$, in some cases, may lead to significant biases in predictions of overall thermal conductivities. It is postulated in the paper that the value of $\lambda_{s}$ can be estimated using the information on the microstructural, intrinsic soil property, namely the specific surface area $(S S A)$. The new model is validated against thirty-four laboratory measurements of thermal conductivity performed on silt and clay soils. For validation purposes five widely known models, predicting overall soil thermal conductivity, are used. The analyses are performed with the use of four different values of solid thermal conductivity. The best agreement between predicted and measured conductivities is obtained when the new model is incorporated into the Johansen's method, i.e. root mean square error (RMSE) and bias are $0.172 \mathrm{Wm}^{-1} \mathrm{~K}^{-1}$ and $-0.040 \mathrm{Wm}^{-1} \mathrm{~K}^{-1}$, respectively.
\end{abstract}

\section{INTRODUCTION}

Heat transfer in solids is commonly described as the conductive flow. In some cases other mechanisms like convection or radiation also may contribute to the overall transfer. This is particularly common in fluids or gases, while in the case of soils, the conductive mechanism overwhelmingly controls (Johansen, 1975). The main parameters affecting the transfer of energy through a soil are the thermal conductivity and the specific heat (Farouki, 1981). The thermal conductivity of a soil $\lambda$ (being an interest of this work) can be defined as the amount of heat which is passing through a unit cross sectional area of a medium in a unit time due to a unit temperature gradient applied in the direction of this heat flow. This particular soil parameter can be determined either by in situ/laboratory measurements or by making use of existing empirical/semi-theoretical models.

In general, the methods for measuring thermal conductivity of soils can be classified into two categories, i.e. steady-state and transient heat transfer methods (Mohsenin, 1980). The steady state methods require a long time to complete the measurement. This is triggered by the fact that a soil portion under study should be in a steady state when the investigation is made. Transient methods usually require much less time and, in addition, are more versatile and easily performed (De Vries and Peck, 1958). Recently, the line source method, using a steel needle probe as a heating source, is most widely used (see Nicolas et al., 1993; Hanson et al., 2000; Różański and Sobótka, 2013; Łydżba et al., 2014a).

Thermal conductivity of soils (among other factors) strongly depends on mineral composition, texture, dry density $\rho_{d}$, moisture content $\theta$, porosity $n$, etc. Hence, much effort has been made to develop models incorporating these soil parameters which can be evaluated from laboratory investigations (Mickley, 1951; Gemant, 1952; Woodside and Messmer, 1961; De Vries, 1963; Johansen, 1975; Campbell, 1985; Coté and Konrád, 2005; Lu et al., 2007; Lu et al., 2014). The majority of these empirical or semitheoretical relations need the soil solid thermal conductivity $\left(\lambda_{s}\right)$ as an input parameter. On the other hand, a proper evaluation of $\lambda_{s}$ requires cumbersome and time consuming laboratory measurements which are in contradiction with a quick prediction of the thermal conductivity. In practice, the conductivity of solids can be directly assumed to be a constant value (Farouki, 1981), it can be predicted from the quartz content of the total solids content (Johansen, 1975) or it can be estimated on the basis of the percent of clay in the soil solids (Gemant, 1952). However, as it is shown further in the paper, all existing models are sensitive to the chosen value of $\lambda_{s}$. Therefore, a proper estimation of solid conductivity $\lambda_{s}$ is required to obtain a good prediction of the overall soil conductivity. The objective of this study is to formulate a simple model, 
that can be used for determination of $\lambda_{s}$, as a function of the specific surface area (SSA) which is a measure directly related to the clay fraction content, clayey mineral type as well as to the organic matter content. Furthermore, $S S A$ is an intrinsic microstructure property which depends on both size and shape of soil particle, and various overall soil properties, used in engineering practice, are strongly affected by the magnitude of the specific surface area (e.g. Dolinar et al., 2007; Yukselen-Aksoy and Kaya, 2010; KoszelaMarek, 2014). The new model is validated against laboratory measurements of thermal conductivity of thirty-four saturated soils. For validation purposes five widely known models, predicting overall soil thermal conductivity, are used.

\section{MATERIALS AND LABORATORY MEASUREMENTS}

Thirty-four soils from three different mining regions of south-western Poland (Lower Silesia region) were used in the study. The soils were extracted from the depth ranging from approximately $77 \mathrm{~m}$ to $320 \mathrm{~m}$ below the ground level. The degree of saturation $S_{r}$, of all investigated soils, was estimated to be in the range from 0.95 to 1 . It is, therefore, assumed that the soils were fully saturated, i.e. $\theta=\theta_{\text {sat }}$. The soils were characterized as silt-clay or clay. The sample notations as well as basic characteristics - the contents of clay $(\mathrm{Cl})$, silt $(\mathrm{Si})$ and sand $(\mathrm{Sa})$; specific surface area $(S S A)$; dry bulk density $\left(\rho_{d}\right)$; soil particle density $\left(\rho_{s}\right)$; moisture content $(\theta)$; porosity $(n)$ - are listed in Table 1. The water content, bulk and particle densities and soil particle size distribution were determined according to the guidelines of CEN ISO/TS 17892 standard (2004). In particular, the particle size distribution was evaluated using the aerometric and sedimentation methods. The specific surface area was measured by making use of the methylene blue adsorption method (e.g. KoszelaMarek, 2014). These measurements have been performed by extended team and the results have been archived in following reports: SPR 1 (2013), SPR 2 (2013) and SPR 1 (2014). For the purposes of this paper only a small part of all results (saturated clayey soils with negligible content of organic matter) was chosen.

The thermal conductivities were measured on intact soil cores by the needle probe test (at ambient temperature, approximately $20{ }^{\circ} \mathrm{C}$ ) with the use of KD2 Pro meter with TR-1 sensor (KD2 Pro Operator's Manual, 2011). Before the measurement was conducted, first, the soil cores of length approximately $50 \mathrm{~cm}$ and of radius equal to $7.5 \mathrm{~cm}$ had been divided into three specimens (say I, II and III) of equal length, roughly $16 \mathrm{~cm}$. Then, each specimen was measured three times; the TR-1 sensor (of length $10 \mathrm{~cm}$ ) was pressed by hand and embedded parallel to the longer side of the specimen, one by one with required time shift, in three (say 1, 2, 3) different locations (see Fig. 1). Final result, overall thermal

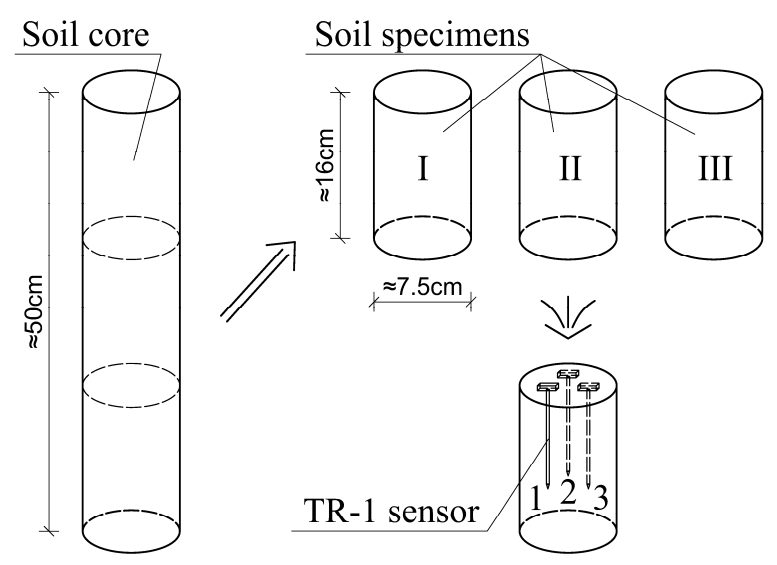

Fig. 1 Graphical illustration of the measurement procedure of thermal conductivity.

conductivity for a given soil core, was evaluated as a mean value from all performed measurements (three different locations for each specimen). The results are summarized in the last column of Table 1. It should be noted, that in the case of highly compacted soils, the sensor insertion was followed by the pilot hole bored by the drill of the diameter nearly equal to the diameter of the sensor. In this case, thermal grease was applied to reduce contact resistance errors with pre-drilled holes.

During each test a steel needle probe is heated for a time period $t_{h}=150$ seconds (a half of the total measurement time). The temperature changes, for heating and cooling phases, are recorded and these data are fit to the following equations (in the majority of our measurements the range of temperatures was $\left.20{ }^{\circ} \mathrm{C} \pm 1.5^{\circ} \mathrm{C}\right)$ :

$T=m_{0}+m_{1} t+m_{3} \ln t$,

for heating, and:

$T=m_{1}+m_{2} t+m_{3} \ln \left(\frac{t}{t-t_{h}}\right)$,

for cooling phase (KD2 Pro Operator's Manual 2011). In the equations above $T$ is the temperature, $t$ is the time, $m_{0}$ and $m_{l}$ is the ambient temperature for heating and cooling phase, respectively, $m_{2}$ is the rate of background temperature drift and $m_{3}$ is the slope of a line that relates temperature increase to $\ln t$. Since (1) and (2) are log time approximations (KD2 Pro Operator's Manual 2011, Łydżba et al. 2014a) the early time data are ignored, i.e. only the final $2 / 3$ of the data collected (during heating and cooling) are used for fitting. Finally, the thermal conductivities are evaluated using the relation:

$\lambda_{\text {measured }}^{T R-1}=\frac{Q}{4 \pi m_{3}}$,

where $Q$ denotes the applied heat input rate. It should 
Table 1 Notations, basic characteristics and thermal conductivities of soils (Report SPR 1 2013, Report SPR 2 2013 and Report SPR 1 2014).

\begin{tabular}{|c|c|c|c|c|c|c|c|c|c|}
\hline Sample & $\begin{array}{l}C l \\
\% \\
\end{array}$ & $\begin{array}{l}S i \\
\%\end{array}$ & $\begin{array}{r}S a \\
\% \\
\end{array}$ & $\begin{array}{l}\boldsymbol{S S A} \\
\mathrm{m}^{2} / \mathrm{g}\end{array}$ & $\begin{array}{r}\boldsymbol{\rho}_{\boldsymbol{d}} \\
\mathrm{g} / \mathrm{cm}^{3}\end{array}$ & $\begin{array}{r}\boldsymbol{\rho}_{\boldsymbol{s}} \\
\mathrm{g} / \mathrm{cm}^{3}\end{array}$ & $\begin{array}{r}\boldsymbol{\theta}=\boldsymbol{\theta}_{\text {sat }} \\
\%\end{array}$ & $\begin{array}{l}n \\
-\end{array}$ & $\begin{array}{c}\lambda_{\text {measured }}^{T R-1} \\
\mathrm{Wm}^{-1} \mathrm{~K}^{-1}\end{array}$ \\
\hline S 01 & 36 & 58 & 6 & 93.0 & 1.66 & 2.61 & 21.9 & 0.364 & 1.897 \\
\hline S_02 & 43 & 45 & 12 & 101.7 & 1.97 & 2.58 & 11.9 & 0.235 & 2.505 \\
\hline $\mathrm{S} \_03$ & 39 & 49 & 12 & 127.3 & 1.88 & 2.65 & 15.6 & 0.292 & 1.904 \\
\hline S_04 & 54 & 46 & 0 & 148.5 & 1.61 & 2.56 & 22.9 & 0.370 & 1.642 \\
\hline $\mathrm{S}_{-}^{-} 05$ & 36 & 58 & 6 & 103.9 & 1.52 & 2.63 & 27.9 & 0.423 & 1.494 \\
\hline S_06 & 70 & 24 & 6 & 90.7 & 1.62 & 2.61 & 23.4 & 0.379 & 1.780 \\
\hline S_07 & 58 & 37 & 5 & 102.3 & 1.73 & 2.67 & 20.3 & 0.351 & 1.943 \\
\hline S_08 & 41 & 57 & 2 & 88.5 & 1.80 & 2.62 & 17.4 & 0.313 & 2.230 \\
\hline S_09 & 46 & 50 & 4 & 121.9 & 1.97 & 2.68 & 13.4 & 0.264 & 2.103 \\
\hline $\mathrm{S} \_10$ & 7 & 92 & 1 & 59.6 & 1.51 & 2.63 & 28.2 & 0.426 & 1.960 \\
\hline $\mathrm{S} \_11$ & 41 & 32 & 27 & 57.0 & 1.75 & 2.63 & 19.2 & 0.335 & 2.325 \\
\hline $\mathrm{S} \_12$ & 58 & 37 & 5 & 129.3 & 1.51 & 2.60 & 27.6 & 0.418 & 1.721 \\
\hline $\mathrm{S} \_13$ & 36 & 28 & 36 & 90.4 & 1.93 & 2.63 & 13.9 & 0.268 & 2.611 \\
\hline $\mathrm{S} \_14$ & 54 & 42 & 4 & 132.6 & 1.94 & 2.65 & 13.8 & 0.267 & 2.098 \\
\hline S_15 & 42 & 57 & 1 & 84.1 & 1.32 & 2.61 & 37.5 & 0.495 & 1.425 \\
\hline S_16 & 60 & 33 & 7 & 102.3 & 1.68 & 2.61 & 21.1 & 0.355 & 2.147 \\
\hline S_17 & 39 & 40 & 21 & 64.9 & 1.85 & 2.60 & 15.5 & 0.287 & 2.553 \\
\hline $\mathrm{S}_{-}^{-} 18$ & 47 & 48 & 5 & 148.1 & 1.25 & 2.24 & 35.2 & 0.441 & 1.439 \\
\hline $\mathrm{S}_{-}^{-} 19$ & 67 & 32 & 1 & 171.7 & 1.67 & 2.64 & 21.9 & 0.366 & 1.426 \\
\hline S_- 20 & 44 & 52 & 4 & 109.0 & 1.84 & 2.63 & 16.3 & 0.300 & 2.004 \\
\hline $\mathrm{S} \_21$ & 31 & 69 & 0 & 119.0 & 1.53 & 2.63 & 27.2 & 0.417 & 1.916 \\
\hline S_- 22 & 35 & 65 & 0 & 63.2 & 1.58 & 2.42 & 22.0 & 0.347 & 1.871 \\
\hline $\mathrm{S} \_23$ & 30 & 63 & 7 & 95.2 & 1.86 & 2.65 & 16.1 & 0.299 & 2.042 \\
\hline S_24 & 31 & 65 & 4 & 78.8 & 1.74 & 2.59 & 18.8 & 0.328 & 1.779 \\
\hline $\mathrm{S}-25$ & 66 & 33 & 1 & 147.1 & 1.59 & 2.61 & 24.6 & 0.391 & 1.511 \\
\hline S_26 & 64 & 35 & 1 & 146.0 & 1.58 & 2.67 & 25.7 & 0.406 & 1.404 \\
\hline S_27 & 46 & 54 & 1 & 86.8 & 1.72 & 2.63 & 20.1 & 0.345 & 1.817 \\
\hline S_28 & 32 & 67 & 1 & 118.3 & 1.67 & 2.63 & 21.9 & 0.365 & 2.083 \\
\hline S_29 & 58 & 28 & 15 & 159.7 & 1.67 & 2.65 & 22.3 & 0.372 & 1.505 \\
\hline S_ 30 & 24 & 75 & 1 & 73.2 & 1.67 & 2.68 & 22.5 & 0.376 & 1.895 \\
\hline $\mathrm{S} \_31$ & 40 & 59 & 1 & 112.4 & 1.64 & 2.63 & 23.1 & 0.378 & 1.603 \\
\hline S_- 32 & 13 & 87 & 0 & 55.8 & 1.63 & 2.62 & 23.0 & 0.376 & 2.190 \\
\hline $\mathrm{S}_{-}^{-} 33$ & 31 & 69 & 0 & 90.4 & 1.77 & 2.62 & 18.2 & 0.323 & 1.926 \\
\hline S_- 34 & 71 & 24 & 5 & 76.9 & 1.82 & 2.64 & 17.0 & 0.310 & 2.136 \\
\hline
\end{tabular}

be emphasized that after each measurement the fitting quality was assessed by the relative error (err), which is a measure of how well the model (Eqs. (1) and (2)) fits the recorded data. According to the user's manual (KD2 Pro Operator's Manual, 2011) a good data set gives err values below 0.01 . If the err value is larger than 0.01 the data has to be discarded and another reading is taken.

\section{EXISTING MODELS}

\subsection{THERMAL CONDUCTIVITY OF SOIL}

As mentioned in the Introduction, there exists a large number of soil thermal conductivity prediction methods. The majority of these models have some limits - in other words, their usefulness is limited to a specific type of soil being under particular conditions, e.g. saturation level, texture and frozen or unfrozen state. A brief summary of existing models (used within this study) recognized by Farouli (1981) as the best models to apply to saturated, unfrozen fine soils will be presented below. Thermal conductivities are expressed in metric units, i.e. $\mathrm{Wm}^{-1} \mathrm{~K}^{-1}$, while the porosity $n$ is dimensionless.

\subsubsection{MICKLEY'S METHOD}

Mickley considered the unit cube of soil as the volume composed of subdomains (columns) being a solid, water and air (Mickley, 1951). For the given direction of heat flow the contributions of each subdomain are added and the thermal conductivity 
(with the assumption of full saturation, $S_{r}=1$ ) is given by the following equation:

$\lambda=\lambda_{w} l^{2}+\lambda_{s}(1-l)^{2}+\frac{2 \lambda_{s} \lambda_{w} l(1-l)}{\lambda_{s} l+\lambda_{w}(1-l)}$

where $\lambda_{w}$ is the thermal conductivity of water and the length of the column $l[-]$ (dimensionless) can be calculated, using the information on soil porosity $n$, i.e.:

$3 l^{2}-2 l^{3}=n$.

\subsubsection{GEMANT'S METHOD}

Gemant considered the moist soil with the contact between soil particles as the point one (Gemant, 1952). The water was assumed to collect around these contact points forming a thermal bridge. Gemant's approach yields the following correlation:

$\frac{1}{\lambda}=\frac{[(1-a) / a]^{4 / 3} \arctan \left[\left(\lambda_{s}-\lambda_{w}\right) / \lambda_{w}\right]^{1 / 2}}{(h / 2)^{1 / 3}\left[\lambda_{w}\left(\lambda_{s}-\lambda_{w}\right)\right]^{3 / 2}}+\frac{1-z}{\lambda_{s} a} \mathrm{f}\left\{\frac{b^{2}}{a}\right\}$,

where

$a=4.869 \sqrt{\rho_{d}} \quad[-]$,

$h=9.988 \cdot 10^{-3} \rho_{d} \theta-h_{0} \quad[-]$,

$z=(1-a / a)^{2 / 3}(h / 2)^{1 / 3} \quad[-]$,

$b^{2}=[a /(1-a)]^{2 / 3}(h / 2)^{2 / 3} \quad[-]$,

In the equations above, $\rho_{d}$ is soil dry density $\left[\mathrm{g} / \mathrm{cm}^{3}\right], \theta$ is moisture content $[\%], h$ represents the apex water (water collected around the contact points), $h_{0}[-]$ is a water adsorbed as a film around the soil particles. Adsorbed water $h_{0}$ is a function of temperature and should be recorded from the appropriate diagram. For the value of temperature $20^{\circ} \mathrm{C}$, it is found that $h_{0}=0.01$. The values of the function $\mathrm{f}\left\{b^{2} / a\right\}$ have to be estimated using another diagram provided by Gemant (1952). For the purpose of this work, as well as for better efficiency of this method, it is found - by fitting the data from (Gemant 1952) - that this function can be approximated using the expression below:

$\mathrm{f}\left\{\frac{b^{2}}{a}\right\}=\frac{1}{0.976+0.2355 \ln \left(b^{2} / a\right)} \quad[-]$.

\subsubsection{W-M METHOD}

Woodside and Messmer approach, which is based on the well-known three resistor model (originally formulated for the electrical conductivity), leads to the following correlation (Woodside and Messmer, 1961):

$\lambda=(n-0.03) \lambda_{w}+(1-n+0.03)\left[\frac{1-n}{\lambda_{s}(1-n+0.03)}+\frac{0.03}{\lambda_{w}(1-n+0.03)}\right]^{-1}$.

\subsubsection{DE VRIES' METHOD}

Within the De Vries model, saturated soil is treated as a two-phase material composed of ellipsoidal soil particles embedded in continuous medium of water. This prediction is given as (De Vries, 1963):

$\lambda=\frac{n \lambda_{w}+(1-n) \lambda_{s} F}{n+(1-n) F}$,

where $F$ is the factor expressed by following relation:

$F=\frac{1}{3} \sum_{i}\left[1+\left(\frac{\lambda_{s}}{\lambda_{w}}-1\right) g_{i}\right]^{-1} \quad[-], \quad i=a, b, c$ 
In the equation above the $g$ values, which were originally intended to be shape factors, are used rather as parameters to fit empirical data. Note that the $g$ values sum to unity, i.e. $g_{a}+g_{b}+g_{c}=1$.

\subsubsection{JOHANSEN'S METHOD}

Johansen expressed the thermal conductivity of an unsaturated soil as a function of both thermal conductivity at saturated state $\left(\lambda_{\text {sat }}\right)$ and the one at dry state $\left(\lambda_{d r y}\right)$ (Johansen, 1975). The concept of normalized thermal conductivity $K_{e}$ (called Kersten's number) was introduced:

$K_{e}=\left(\lambda-\lambda_{d r y}\right) /\left(\lambda_{s a t}-\lambda_{d r y}\right) \quad[-]$.

A semi-empirical relation, based on the dry density, was formulated to estimate $\lambda_{d r y}$, while the thermal conductivity at saturated state $\lambda_{\text {sat }}$ was proposed to be estimated using the geometric mean, "average" of the parallel and series thermal conductivities, i.e.:

$\lambda_{\text {sat }}=\lambda_{w}^{n} \lambda_{s}^{(1-n)}$.

Kersten's number $\left(K_{e}\right)$, for fine textured soils, was related to the degree of saturation $S_{r}$ by the following formula:

$K_{e}=\log S_{r}+1.0 \quad[-]$.

Therefore, it is evident that in the case of fully saturated soils $\left(S_{r}=1\right)$, Kersten's number is also taking the value of 1, and using Eqs. (15) and (16), we obtain the formula for the thermal conductivity at saturation, i.e. $\lambda=\lambda_{\text {sat }}=\lambda_{w}^{n} \lambda_{s}^{(1-n)}$.

\subsection{THERMAL CONDUCTIVITY OF SOIL SOLID}

Each correlation, briefly described above, needs the value of the thermal conductivity of soil solid $\lambda_{s}$ as an input parameter. In the literature, different approaches for evaluation of $\lambda_{s}$ are proposed. Farouki (1981), considering results of different researchers, pointed out that thermal conductivity of soil solid, in the case of silt-clay soils, can be directly assumed as $\lambda_{s}=2.0-3.0 \mathrm{Wm}^{-1} \mathrm{~K}^{-1}$.

Johansen (1975) determined solid conductivity using the geometric mean equation from the quartz content $q$ as a fraction of the total solids content and thermal conductivities of quartz $\lambda_{q}\left(7.7 \mathrm{Wm}^{-1} \mathrm{~K}^{-1}\right)$ and other minerals $\lambda_{o}\left(2.0 \mathrm{Wm}^{-1} \mathrm{~K}^{-1}\right.$ for soils with $q>0.2$, and $3.0 \mathrm{Wm}^{-1} \mathrm{~K}^{-1}$ for $q \leq 0.2$ ), i.e.:

$\lambda_{s}=\lambda_{q}^{q} \lambda_{o}^{(1-q)}$.

The estimation of solid conductivity using Eq. (18) requires, therefore, the measurement of quartz content. This test is not commonly performed. In practice, it is often assumed that quartz content $q$ is equal to the content of sand (Peters-Lidard et al.,
1998). However, it is obvious that in a case of fine soils (being the study of the paper), i.e. when the content of sand fraction is, in general, very low, the geometric mean does not deviate from constant value $3.0 \mathrm{Wm}^{-1} \mathrm{~K}^{-1}$ (being the conductivity of other minerals) by more than a few percent.

Gemant (1952) suggested that thermal conductivity of soil solid can be estimated using the information on the percent of clay in the soil solids $\mathrm{Cl}$ :

$\lambda_{s}=5.84-0.033(\mathrm{Cl})$.

The above equation can lead to underestimation or overestimation of solid conductivity. At one extreme case, i.e. when there is no clay, Farouki (1981) pointed out that Eq. (19) gives $5.84 \mathrm{Wm}^{-1} \mathrm{~K}^{-1}$ which is too low for quartz sand by about $25 \%$. On the contrary, in the case of $100 \%$ of clay, Eq. (19) gives $2.54 \mathrm{Wm}^{-1} \mathrm{~K}^{-1}$ - this value is greater than the minimum one suggested by Farouki (1981) for siltclay soils, namely $2.0 \mathrm{Wm}^{-1} \mathrm{~K}^{-1}$.

\section{THE NEW APPROACH TO EVALUATE THE SOLID CONDUCTIVITY}

Soil mineral composition is an important factor affecting thermal conductivity of the soil solid due to the substantial diversity of thermal conductivity of particular minerals being its constituents (Farouki, 1981). For instance, the thermal conductivity of quartz minerals is approximately 2-3 times higher than the clay ones, e.g. $7.7 \mathrm{Wm}^{-1} \mathrm{~K}^{-1}$ for quartz (Clauser and Huenges, 1995) or $2.9 \mathrm{Wm}^{-1} \mathrm{~K}^{-1}$ for clay minerals (Bristow, 2002). Furthermore, the thermal conductivities of an organic matter $\left(0.25 \mathrm{Wm}^{-1} \mathrm{~K}^{-1}\right)$ and soil minerals differ by one order of magnitude. Hence, the recognition of soil mineral composition plays a vital role in proper evaluation of solid conductivity. In other words, if the mineral composition of soil is well recognized and, in addition, thermal conductivities of particular minerals are given, the conductivity of soil solid can be quite accurately estimated.

In practice, however, the investigation of soil mineral fabric is not commonly conducted. Therefore, there is a need for searching such measures that can directly exhibit the mineral composition of soil solid. It was, in some sense, the idea of Gemant (Eq. (19)) who assumed that as the content of clay fraction is increasing - and as a consequence, the contribution of clay minerals in the solid is also increasing - the conductivity of soil solid should decrease. As mentioned earlier, this approach has some disadvantages at extreme values of clay content.

Hence, for the purpose of solid thermal conductivity estimation, it is proposed to use another microstructural measure, namely the specific surface area $(S S A)$, which is directly related to the clay fraction content, clayey mineral type as well as to the organic part content. The SSA of soil material can variously be defined (Hillel, 1998) but a reasonable definition is that $S S A$ is the total surface area of 
particles per unit mass, expressed in terms of square meters per gram. Specific surface area is an intrinsic microstructure property which depends on both size and shape of soil particle. It is evident that flattened or elongated particles exhibit greater surface per unit mass or volume than spherical particles do. Although the clay minerals have small sizes, their shape is - in general - platy (Fig. 2) and therefore they mainly contribute to the overall value of $S S A$. For example, the $S S A$ of sand may be no more than $1-2 \mathrm{~m}^{2} / \mathrm{g}$, while that of clay may be at least 100 times higher (Hillel, 1998; Mitchell and Soga, 2005). In that sense, SSA appears to be a measure which reveals the mineral composition of soil solid.

According to the proposition of Gemant (Eq. (19)), the solid conductivity is decreasing as the content of clay fraction is increasing. As a consequence, the overall thermal conductivity of soil is also expected to be a decreasing function of $\mathrm{Cl}$. Measured thermal conductivities, for all investigated soils, are plotted in Figure 3a against the clay content. The line of trend visualizes the decreasing thermal conductivity as $\mathrm{Cl}$ increases. The same behaviour is

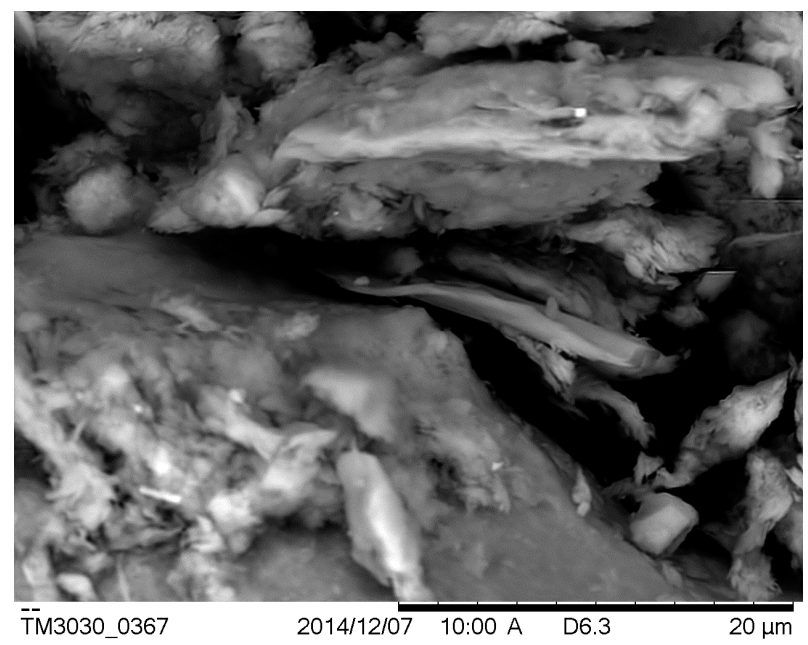

Fig. 2 Microstructure of the chosen clay soil specimen (S_12) under SEM.

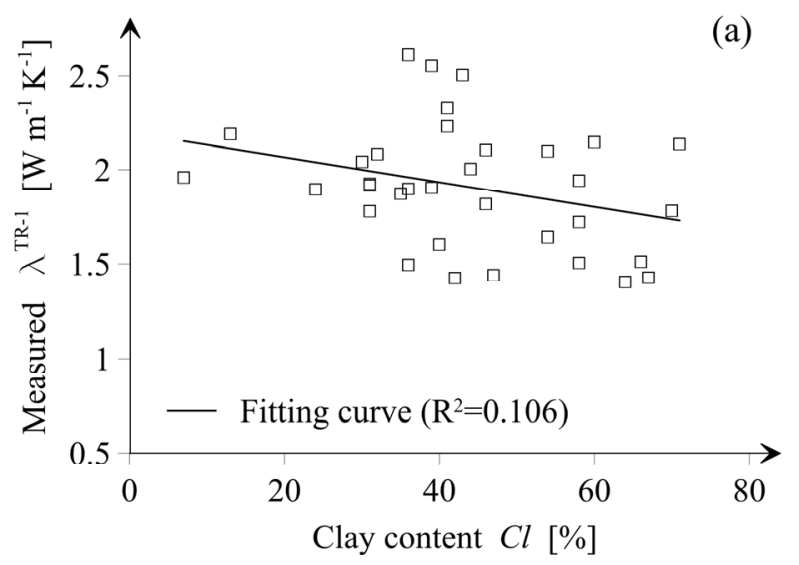

observed in the second graph (Fig. 3b) where measured thermal conductivity is plotted against the specific surface area. Thus, due to the fact that SSA (as well as volume fraction of clay particles) is a microstructural property and the overall soil conductivity depends on its value, it is postulated that it is the solid conductivity $\lambda_{s}$ that is affected by the $S S A$ (similarly as in the case of the proposition of Gemant (1952) where solid conductivity is a function of $C l$ ). It has also been found in the paper of Lydżba et al. (2014b) where micromechanical approaches, namely Mori-Tanaka and Self-Consistent schemes are used to simulate the microstructure of clays.

Since high values of SSA exhibit large contribution of clay minerals in the solid, and bearing in mind the relative difference in conductivities of quartz and clay minerals, it is evident that the value of solid conductivity $\lambda_{s}$ is a decreasing function of specific surface area. The relation between $\lambda_{s}$ and the $S S A$ is postulated to be characterized by the modified power function:

$\lambda_{s}=a_{1} \cdot a_{2}^{S S A}+a_{3}$,

where $a_{1}, a_{2}, a_{3}$ are the parameters to be fit. Note that the choice of the above function is not arbitrary since Eq. (22) should hold the following conditions. As the $S S A$ value tends to zero (no content of clay minerals) the conductivity should be close to that of quartz sand (the value of pure quartz mineral, $7.7 \mathrm{Wm}^{-1} \mathrm{~K}^{-1}$, is prescribed). On the other hand, for the large value of $S S A$, e.g. $800 \mathrm{~m}^{2} / \mathrm{g}$ (such extreme value of $S S A$ is reported for the minerals of the smectite group, e.g. montmorillonite (Mitchell and Soga, 2005; KoszelaMarek, 2014) the minimum value of solid conductivity, found in the literature (Farouki, 1981), namely $2.0 \mathrm{Wm}^{-1} \mathrm{~K}^{-1}$ is assumed. Furthermore, as mentioned earlier, the typical range of $S S A$ for clay soils is 100 to $200 \mathrm{~m}^{2} / \mathrm{g}$ (the average value is $150 \mathrm{~m}^{2} / \mathrm{g}$ ). Thus, taking this into account a third condition is defined: we assign the value of conductivity $3.0 \mathrm{Wm}^{-1} \mathrm{~K}^{-1}$ (which is typical for siltclay soils) to the value of $S S A$ equal to $150 \mathrm{~m}^{2} / \mathrm{g}$. Using the above conditions, a set of points, $\left(S S A, \lambda_{s}\right)$,

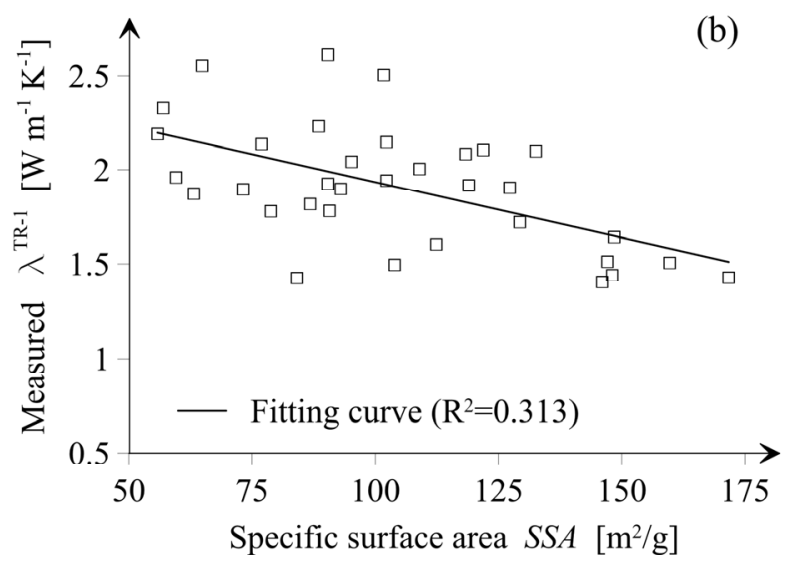

Fig. 3 Measured soil thermal conductivities vs.: (a) content of the clay fraction $\mathrm{Cl}$, (b) specific surface area SSA. 


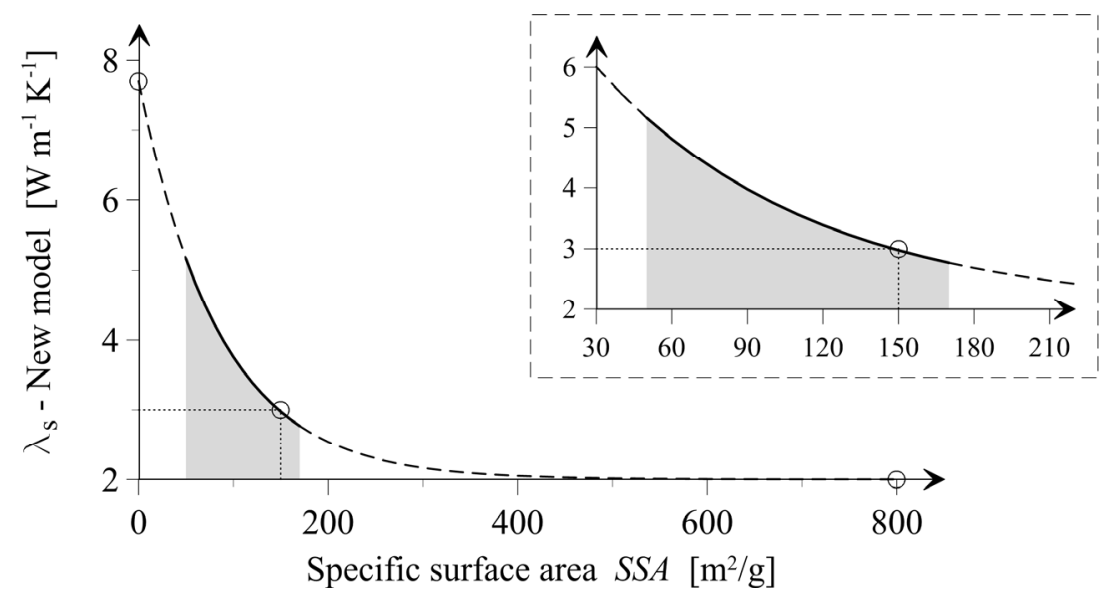

Fig. 4 The postulated dependence of solid thermal conductivity on soil specific surface area (fitting function - Eq. (22)); enlargement of the plot in the range of $S S A$ for which the model is validated.
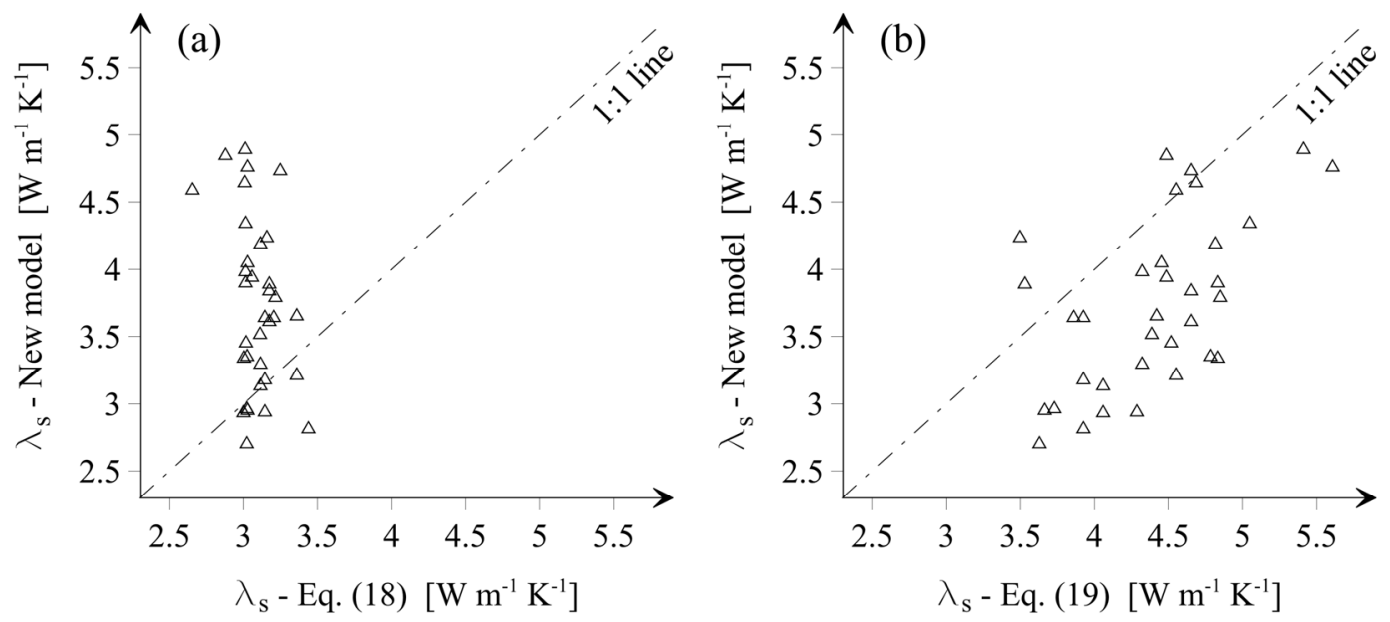

Fig. 5 Solid conductivities predicted by the new model (Eq. (22)) vs.: (a) geometric mean prediction (Eq. (18)), (b) estimation based on the Gemant's approach (Eq. (19)).

i.e. $\{(0,7.7) ;(150,3.0) ;(800,2.0)\}$ creates the data which is used for fitting Eq. (22). The least square method is used and the following values of parameters $a_{1}, a_{2}$ and $a_{3}$ are found: $a_{1}=5.7, a_{2}=0.988, a_{3}=2.0$. The data as well as the fitting function (Eq. (22)) is presented in Figure 4. It has to be emphasized that the proposed model, Eq. (22), is verified for all thirty-four soils, for which the range of $S S A$ is: $55.8-171.7 \mathrm{~m}^{2} / \mathrm{g}$ (see Table 1). The range, in which the model is tested, is also indicated in Figure 4 by the continuous line and filled area under the curve.

\section{RESULTS AND DISCUSSION}

\subsection{THERMAL CONDUCTIVITY OF SOIL SOLID}

The new model - Eq. (22) - was used to predict the solid conductivities of all investigated soils. The solid conductivity, estimated by the new model, is in the range from 2.72 to $4.91 \mathrm{Wm}^{-1} \mathrm{~K}^{-1}$. In Figures $5 \mathrm{a}$ and $5 \mathrm{~b}$ estimations of the new model are plotted against the conductivities obtained with the use of geometric mean (Eq. (18)) and Gemant's method (Eq. (19)), respectively. Furthermore, for ease of comparison, 1:1 line is also provided.

It can be noticed that the results of solid conductivity obtained with the use of the new model are, in general, greater than the ones resulting from the geometric mean. Moreover, as it was expected, the geometric mean estimation, due to the low content of sand fraction, is close to the constant value $3.0 \mathrm{Wm}^{-1} \mathrm{~K}^{-1}$, for all considered soils. The new model gives slightly lower values of solid conductivity, when compared to the Gemant's approach (only five of thirty-four results are above 1:1 line).

\subsection{THERMAL CONDUCTIVITY OF SATURATED SOIL}

All models described in Section 3.1 were used to predict the overall soil conductivities. The results were obtained using four different values of solid 
Table 2 Root mean square error (RMSE) of the Mickley model, Gemant model, W-M model, De Vries model and Johansen model corresponding to four different values of solid conductivity $\lambda_{s}$.

\begin{tabular}{c|cccc}
\hline Method & \multicolumn{4}{c}{ RMSE $\left[\mathrm{Wm}^{-1} \mathrm{~K}^{-1}\right]$} \\
& $\lambda_{s}=3.0$ & $\lambda_{s}-$ Eq. (18) & $\lambda_{s}-$ Eq. (19) & $\lambda_{s}-$ New model \\
\hline Mickley & 0.296 & 0.290 & 0.435 & 0.217 \\
Gemant & 0.504 & 0.483 & 0.218 & 0.258 \\
W-M & 0.243 & 0.267 & 0.619 & 0.368 \\
De Vries & 0.275 & 0.274 & 0.401 & 0.207 \\
Johansen & 0.317 & 0.308 & 0.332 & 0.172 \\
\hline
\end{tabular}

Table 3 Bias of the Mickley model, Gemant model, W-M model, De Vries model and Johansen model corresponding to four different values of solid conductivity $\lambda_{s}$.

\begin{tabular}{c|cccc}
\hline Method & \multicolumn{4}{c}{ Bias $\left[\mathrm{Wm}^{-1} \mathrm{~K}^{-1}\right]$} \\
& $\lambda_{s}=3.0$ & $\lambda_{s}-$ Eq. (18) & $\lambda_{s}-$ Eq. (19) & $\lambda_{s}-$ New model \\
\hline Mickley & 0.176 & 0.135 & -0.378 & -0.128 \\
Gemant & 0.441 & 0.407 & 0.006 & 0.200 \\
W-M & 0.005 & -0.039 & -0.580 & -0.319 \\
De Vries & 0.141 & 0.103 & -0.344 & -0.131 \\
Johansen & 0.215 & 0.179 & -0.261 & -0.040 \\
\hline
\end{tabular}

Table 4 The slope of the trend line of the Mickley model, Gemant model, W-M model, De Vries model and Johansen model corresponding to four different values of solid conductivity $\lambda_{s}$.

\begin{tabular}{c|cccc}
\hline Method & \multicolumn{4}{|c}{ Slope [-] } \\
& $\begin{array}{r}\lambda_{s}=3.0 \\
\mathrm{Wm}^{-1} \mathrm{~K}^{-1}\end{array}$ & $\lambda_{s}-$ Eq. (18) & $\lambda_{s}-$ Eq. (19) & $\lambda_{s}-$ New model \\
\hline Mickley & 0.328 & 0.329 & 0.679 & 0.874 \\
Gemant & 0.358 & 0.362 & 0.657 & 0.798 \\
W-M & 0.301 & 0.298 & 0.640 & 0.865 \\
De Vries & 0.342 & 0.345 & 0.676 & 0.841 \\
Johansen & 0.357 & 0.362 & 0.707 & 0.855 \\
\hline
\end{tabular}

conductivities, i.e. constant value according to suggestion of Farouki (1981), namely $\lambda_{s}=3.0 \mathrm{Wm}^{-1} \mathrm{~K}^{-1}$, the one estimated as the geometric mean (Eq. (18)), the one determined with the use of Gemant's approach (Eq. (19)) and the value of conductivity resulting from the new model (Eq. (22)). The conductivity of water phase was assumed as $\lambda_{w}=0.585 \mathrm{Wm}^{-1} \mathrm{~K}^{-1}$. Predicted conductivities were compared with the laboratory results using the root mean square error (RMSE):

RMSE $=\sqrt{\frac{\sum\left(\lambda_{\text {measured }}^{\text {TR-1 }}-\lambda_{\text {predicted }}\right)^{2}}{m}}$,

and the bias:

bias $=\frac{\sum\left(\lambda_{\text {measured }}^{\text {TR-1 }}-\lambda_{\text {predicted }}\right)}{m}$,

where $\lambda_{\text {measured }}^{T R-1}$ and $\lambda_{\text {predicted }}$ represent measured and predicted values of thermal conductivity, respectively, and $m$ is the number of measurements. The RMSE
(Eq. (23)) and the bias (Eq. (24)) were calculated for all considered cases (four different values of $\lambda_{s}$ ) and they are listed in Tables 2 and 3, respectively. The results are also graphically presented in Figure 6, where predicted thermal conductivities are plotted against the measured ones. For better visualization of results the linear trend as well as 1:1 line is also displayed. In addition, the values of the slope of the trend line are provided in Table 4 (note that as this value is equal to 1 , the trend and 1:1 lines possesses the same slope). For clarity of presentation, in Figure 6 the results corresponding to the constant value of solid conductivity $\left(\lambda_{\mathrm{s}}=3.0 \mathrm{Wm}^{-1} \mathrm{~K}^{-1}\right)$ are not displayed - this is due to fact that these results almost coincide with the ones obtained using the geometric mean (Eq. (18)).

Performed analyses confirmed that the proper estimation of overall thermal conductivity is strongly dependent on the appropriate value of the solid conductivity that is used, as an input parameter, within 

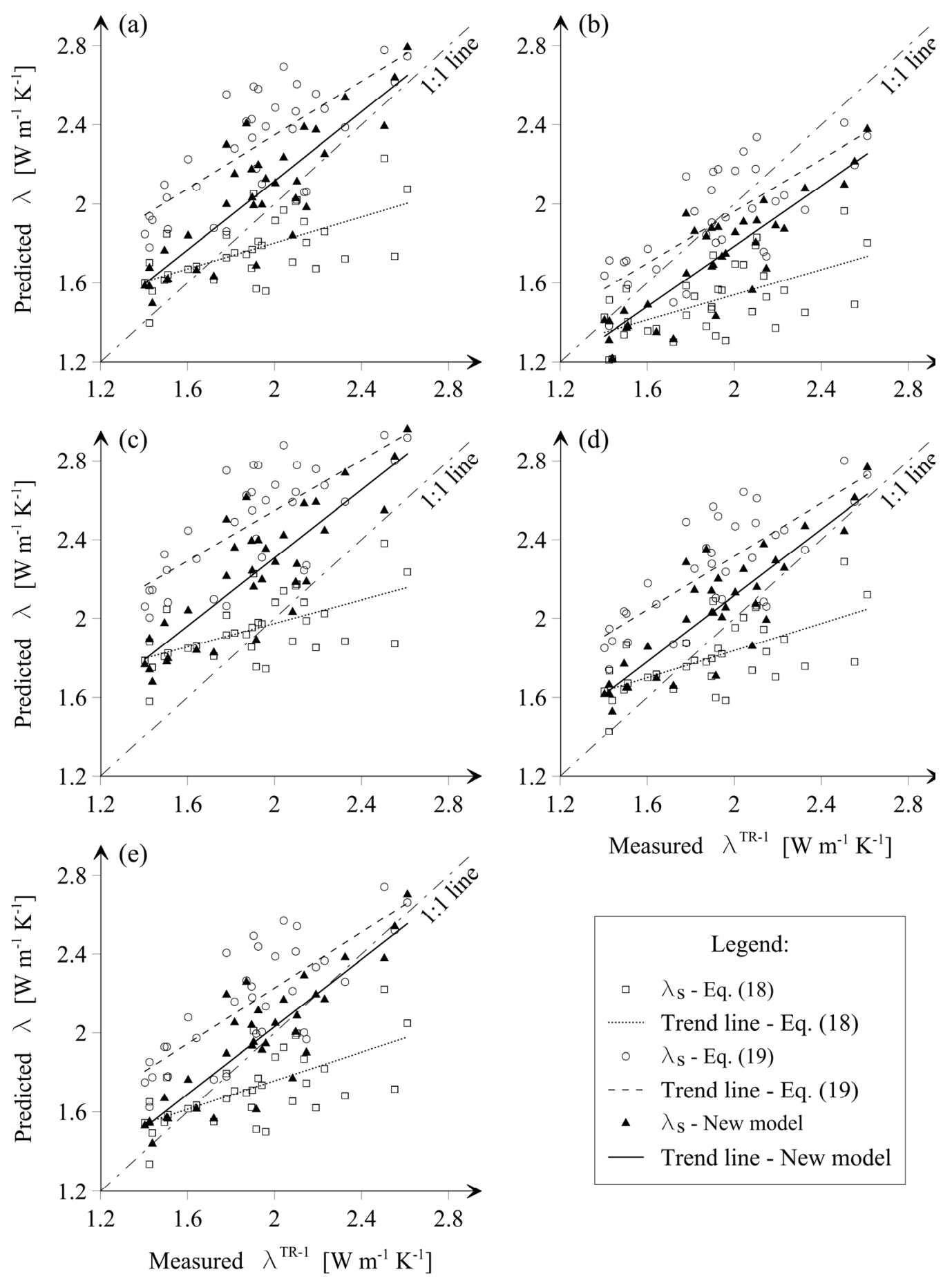

Fig. 6 Comparison of predicted soil thermal conductivity $(\lambda)$ values from (a) Mickley model, (b) Gemant model, (c) W-M model, (d) De Vries model, and (e) Johansen model obtained with three different values of solid conductivity vs. measured data.

the particular model, e.g. the W-M model gives a relatively good prediction (low value of $\mathrm{RMSE}=0.243 \mathrm{Wm}^{-1} \mathrm{~K}^{-1}$ and bias $=-0.005 \mathrm{Wm}^{-1} \mathrm{~K}^{-1}$ ) in the case of the constant value of $\lambda_{s}=3.0 \mathrm{Wm}^{-1} \mathrm{~K}^{-1}$ while it becomes the worst prediction when the $\lambda_{s}$ determined according to Eq. (19) is used - the greatest values of $\mathrm{RMSE}=0.619 \mathrm{Wm}^{-1} \mathrm{~K}^{-1}$ and bias $=0.580 \mathrm{Wm}^{-1} \mathrm{~K}^{-1}$.
In general, the predicted thermal conductivities rather underestimate the measured ones when the calculations are performed with solid conductivity estimated as the geometric mean (Eq. (18)) and overestimate them when $\lambda_{s}$, evaluated by Gemant's expression (Eq. (19)), is used. The results obtained with the solid conductivity as a constant value or with $\lambda_{s}$ as the geometric mean almost coincide. 
Furthermore, when $\lambda_{s}$ is a constant value or it is estimated as the geometric mean, the slope of the trend line is significantly different than $1: 1$ line. This fact is the most evident in the case of W-M method one can see (Fig. 6) that in spite the RMSE and bias are relatively small, some results strongly overestimate while others underestimate the measured conductivities (the dividing point is around $\lambda=2.0 \mathrm{Wm}^{-1} \mathrm{~K}^{-1}$ ) - the slope is 0.301 and 0.298 for $\lambda_{s}=3.0 \mathrm{Wm}^{-1} \mathrm{~K}^{-1}$ and $\lambda_{s}$ determined as the geometric mean, respectively.

When the new model is not taken into consideration, the best agreement between predicted and measured thermal conductivities is obtained in the case of Gemant's method with the value of $\lambda_{s}$ estimated according to Eq. (19) - $\mathrm{RMSE}=0.218 \mathrm{Wm}^{-1} \mathrm{~K}^{-1}$ and bias $=0.006 \mathrm{Wm}^{-1} \mathrm{~K}^{-1}$. Nevertheless, this method is the most cumbersome one among all considered models. This is due to the fact that within this model the variation of adsorbed water $\left(h_{0}\right)$ with temperature as well as the variation of the function $\mathrm{f}\left\{b^{2} / a\right\}$ with the soil dry density and moisture content (see Chapter 3.2) has to be estimated using diagrams provided by Gemant (1952). Furthermore, the value of the slope, 0.657 , is still not satisfactory - some results are underestimated while others are overestimated.

Focusing now on the results obtained with the use of the new model (Eq. (22)), the following conclusions can be drawn. Considering RMSE and bias only, the new model gives better predictions for all methods, except four cases, namely: Gemant's method with $\lambda_{s}$ estimated by his own proposition (Eq. (18)), W-M model with $\lambda_{s}=3.0 \mathrm{Wm}^{-1} \mathrm{~K}^{-1}$ or with $\lambda_{s}$ estimated as the geometric mean and De Vries model with solid conductivity evaluated as the geometric mean. On the other hand, it is most remarkable that when one considers the slope of the trend line it can be seen that the predictions obtained by the new model are significantly improved, i.e. for all models when $\lambda_{s}=3.0 \mathrm{Wm}^{-1} \mathrm{~K}^{-1}$ the slope is in the range from 0.301 to $0.358, \lambda_{s}$ evaluated according to Gemant proposition gives the slope from 0.640 to 0.707, in the case of geometric mean it is from 0.298 to 0.362 , while using the new model the slope is in the range from 0.798 to 0.874 .

Finally, the best prediction is obtained when the new model is used as an input parameter within the Johansen's method, i.e. $\mathrm{RMSE}=0.172 \mathrm{Wm}^{-1} \mathrm{~K}^{-1}$, bias $=-0.040 \mathrm{Wm}^{-1} \mathrm{~K}^{-1}$ and the slope is 0.855 .

\section{FINAL CONCLUSIONS}

It was shown that all correlations (existing in the literature), used to predict thermal conductivities of saturated clayey soils, are sensitive to the chosen value of the soil solid conductivity $\lambda_{s}$. Laboratory measurement of the solid conductivity is a difficult task. As a consequence, different researchers have attempted to find the model for proper estimation of $\lambda_{s}$. Nevertheless, the analyses performed in this work showed that using either one constant value of solid conductivity $\lambda_{s}=3.0 \mathrm{Wm}^{-1} \mathrm{~K}^{-1}$ (as suggested by Farouki (1981)), estimating it as the geometric mean (Eq. (18)) or evaluating on the basis of clay content (Gemant's approach - Eq. (19)) may lead to significant biases in predictions of overall thermal conductivities.

It is obvious that soil solid conductivity is affected by its mineral composition due to the substantial diversity of thermal conductivity of particular minerals being its constituents and therefore the appropriate recognition of soil mineral composition plays a vital role in proper evaluation of solid conductivity. It was postulated, in the paper, that this can be performed, indirectly, by the investigation of soil specific surface area, i.e. as the value of $S S A$ is increasing, the contribution of clay minerals (in soil solid) is also increasing, and as a consequence the thermal conductivity of solid should decrease. The relation between $\lambda_{s}$ and the $S S A$ was postulated to be characterized by the modified power function Eq. (22). The new model was validated against laboratory data, i.e. thirty-four soil samples (range of SSA: $55.8-171.7 \mathrm{~m}^{2} / \mathrm{g}$ ) were used. The predictions of overall thermal conductivity were obtained using five widely known correlations, namely: Mickley model, Gemant model, W-M model, De Vries model and Johansen model. The best prediction was obtained when the new model was incorporated into the Johansen's expression and therefore this correlation is suggested to be used when the thermal conductivity of saturated clayey soils is estimated.

\section{REFERENCES}

Bristow, K.L.: 2002, Thermal conductivity. Methods of Soil Analysis, Soil Science Society of America, Inc., Madison, 1209-1226.

Campbell, G.S.: 1985, Soil physics with BASIC: Transport models for soil-plant systems. Elsevier Sci. Publ. Co., New York.

CEN ISO/TS 17892: 2004, Geotechnical investigation and testing - Laboratory testing of soil. International Organization for Standardization, Geneva, Switzerland.

Clauser, C. and Huenges, E.: 1995, Thermal conductivity of rocks and minerals. Rock Physics \& Phase Relations: A Handbook of Physical Constants (ed. T.J. Ahrens), American Geophysical Union, Washington, D. C. DOI: 10.1029/RF003p0105

Coté, J. and Konrad, J.M.: 2005, A generalized thermal conductivity model for soils and construction materials. Can. Geotech. J., 42, 443-458. DOI: $10.1139 / \mathrm{cgj}-2013-0388$

De Vries, D.A. and Peck, A.J: 1958, On the cylindrical probe method of measuring thermal conductivity with special reference to soils. Austr. Journal of Physics, 11.

De Vries, D.A.: 1963, Thermal properties of soils. W.R. Van Wijk (ed.) Physics of plant environment, NorthHolland Public Co., Amsterdam.

Dolinar, B., Mišič, M. and Trauner, L.: 2007, Correlation between surface area and Atterberg limits of finegrained soils. Clays and Clay Miner., 55, 519-523. DOI: 10.1346/CCMN.2007.0550506 
Farouki, O.T.: 1981, Thermal properties of soils. CRREL Monograph, 81-1, New Hampshire.

Gemant, A.: 1952, How to compute thermal soil conductivities. Heating, Piping and Air Conditioning, $24(1), 122-123$.

Hanson, J.L., Edil, T.B. and Yesiller, N.: 2000, Thermal properties of high water content materials. Geotechnics of High Water Content Materials, T.B. Edil and P.J. Fox (eds.), West Conshohocken, PA, 137-151.

Hillel, D.: 1998, Environmental soil physics: Fundamentals, applications, and environmental considerations. Academic press.

Johansen, O.: 1975, Thermal conductivity of soils. Ph.D. diss., Norwegian Univ. of Science and Technology, Trondheim.

KD2 Pro Thermal Properties Analyzer Operator's Manual: 2011, Version 10, Decagon Devices, Inc.

Kersten, M.S.: 1949, Laboratory research for the determination of the thermal properties of soils. ACFEL Tech. Tech. Rep., 23, Univ. of Minnesota, Minneapolis.

Koszela-Marek, E.: 2014, The effect of 200 MPa pressure on specific surface area of clay. Studia geotechnica et mechanica, 36 (4), 3-6. DOI: $10.2478 /$ sgem-2014-0030

Lu, S., Ren, T., Gong, Y. and Horton, R.: 2007, An improved model for predicting soil thermal conductivity from water content at room temperature. Soil Science Society of America Journal, 71 (1), 8-14. DOI: $10.2136 /$ sssaj2006.0041

Lu, Y., Lu, S. Horton, R. and Ren, T.: 2014, An empirical model for estimating soil thermal conductivity from texture, water content, and bulk density. Soil Science Society of America Journal, 78 (6), 1859-1868. DOI: 10.2136/sssaj2014.05.0218

Łydżba, D., Różański, A., Rajczakowska, M. and Stefaniuk, D.: 2014a, Efficiency of the needle probe test for evaluation of thermal conductivity of composite materials: two-scale analysis. Studia geotechnica et mechanica, 36 (1), 55-62. DOI: $10.2478 /$ sgem-2014-0007

Łydżba, D., Rajczakowska, M., Różański, A. and Stefaniuk, D.: 2014b, Influence of the moisture content and temperature on the thermal properties of soils: laboratory investigation and theoretical analysis. Procedia Engineering, 91, 298-303. DOI: 10.1016/j.proeng.2014.12.064
Mickley, A.S.: 1951, The thermal conductivity of moist soil. American Institute of Electrical Engineers Transactions, 70, 1789-1797.

Mitchell, J. and Soga, K.: 2005, Fundamentals of soil behavior. John Wiley and Sons, Inc., Hoboken, NJ.

Mohsenin, N.N.: 1980, Thermal properties of foods and agricultural materials. Gordon and Breach, New York.

Nicolas, J., Andr'e, P., Rivez, J.F. and Debbaut, V.: 1993, Thermal conductivity measurements in soil using an instrument based on the cylindrical probe method. Review of Scientific Instruments, 64, No. 3, 774-780. DOI: 10.1063/1.1144158

Peters-Lidard, C.D., Blackburn, E., Liang, X. and Wood, E.F.: 1998, The effect of soil thermal conductivity parameterization on surface energy fluxes and temperatures. Journal of the Atmospheric Sciences, 55(7), 1209-1224.

DOI: $10.1175 / 1520$ 0469(1998)055<1209:TEOSTC $>2.0$. CO;2

Report SPR 1: 2013, Report from the measurements of mechanical and thermal properties of soils. Wroclaw University of Technology, I10/2013/S-001.

Report SPR 2: 2013, Report from the measurements of mechanical and thermal properties of soils. Wroclaw University of Technology, I10/2013/S-002.

Report SPR 1: 2014, Report from the measurements of mechanical and thermal properties of soils. Wroclaw University of Technology, I10/2014/S-001.

Różański, A. and Sobótka, M.: 2013, On the interpretation of the needle probe test results: thermal conductivity measurement of clayey soils. Studia Geotechnica et Mechanica, 35(1), 195-207, DOI: $10.2478 /$ sgem-2013-0015

Woodside, W. and Messmer, J.M.: 1961, Thermal conductivity of porous media. Journal of Applied Physics, 32 (9), 1688-1706. DOI: 10.1063/1.1728420

Yukselen-Aksoy, Y. and Kaya, A.: 2010, Method dependency of relationships between specific surface area and soil physicochemical properties. Applied Clay Science, 50, 182-190.

DOI: $10.1016 /$ j.clay.2010.07.020 